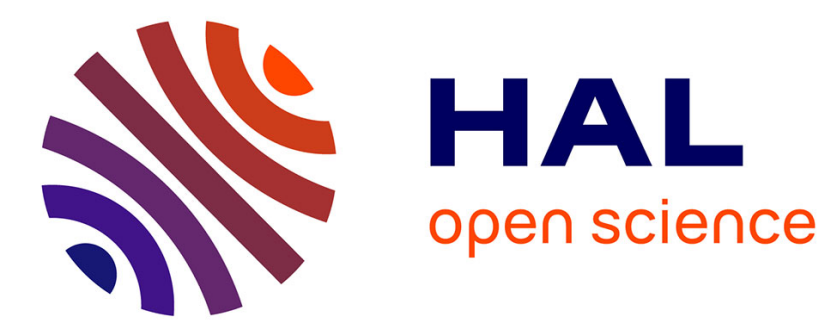

\title{
Validation of Upper-Tropospheric Humidity from SAPHIR on board Megha-Tropiques Using Tropical Soundings
}

Hélène Brogniez, Gaëlle Clain, Rémy Roca

\section{- To cite this version:}

Hélène Brogniez, Gaëlle Clain, Rémy Roca. Validation of Upper-Tropospheric Humidity from SAPHIR on board Megha-Tropiques Using Tropical Soundings. Journal of Applied Meteorology and Climatology, 2015, 54, pp.896-908. 10.1175/JAMC-D-14-0096.1 · hal-01111792

\author{
HAL Id: hal-01111792 \\ https://hal.science/hal-01111792
}

Submitted on 21 Nov 2020

HAL is a multi-disciplinary open access archive for the deposit and dissemination of scientific research documents, whether they are published or not. The documents may come from teaching and research institutions in France or abroad, or from public or private research centers.
L'archive ouverte pluridisciplinaire $\mathbf{H A L}$, est destinée au dépôt et à la diffusion de documents scientifiques de niveau recherche, publiés ou non, émanant des établissements d'enseignement et de recherche français ou étrangers, des laboratoires publics ou privés. 


\title{
Validation of Upper-Tropospheric Humidity from SAPHIR on board Megha-Tropiques Using Tropical Soundings
}

\author{
HÉLÈne BROGNIEZ AND GAËLle Clain \\ Laboratoire Atmosphères, Milieux, Observations Spatiales, Guyancourt, France \\ RÉMY ROCA \\ Laboratoire d'Etudes en Géophysique et Océanographie Spatiales, Toulouse, France
}

(Manuscript received 23 April 2014, in final form 9 January 2015)

\begin{abstract}
This paper describes the upper-tropospheric humidity (UTH) product derived from brightness temperature measurements of the Sondeur Atmosphérique du Profil d'Humidité Intertropicale par Radiométrie (SAPHIR) radiometer on board the Megha-Tropiques satellite. Under nonscattering conditions, the observations from three channels of SAPHIR-located at $\pm 0.2, \pm 1.1$, and $\pm 2.8 \mathrm{GHz}$, respectively, around the 183.31-GHz strong water vapor absorption band-are interpreted into three different UTHs following a wellestablished method and thus describing the humidity content of the upper to midtroposphere. The evaluation of the UTHs is performed using reference UTHs defined from relative humidity (RH) profiles from radiosoundings of two field campaigns: the Cooperative Indian Ocean Experiment on Intraseasonal Variability in the Year 2011/Dynamics of the Madden-Julian Oscillation/Atmospheric Radiation Measurement Program Madden-Julian Oscillation Investigation Experiment (CINDY/DYNAMO/AMIE) and a Megha-Tropiques dedicated campaign in Ouagadougou, Burkina Faso, during the summer of 2012. A budget of the various uncertainties associated with each component of the evaluation method (such as the radiometric sensitivity and the radiative transfer computations) was created to achieve a more robust comparison between the two UTH estimates. The comparison between the reference UTHs and the SAPHIR UTHs reveals small global biases of lower than $2 \% \mathrm{RH}$ on average, with correlation coefficients between 0.86 and 0.89 . Taking into account the individual uncertainties gives root-mean-square errors of regressions that range between $0.92 \%$ and $4.71 \%$. These three UTHs provide a vertical distribution of the RH that is suitable for studying various temporal and spatial scales of the tropical variability. The signature of a mesoscale convective system on its environment is briefly presented to illustrate the capability of this new dataset.
\end{abstract}

\section{Introduction}

The distribution of relative humidity (RH) in the free troposphere is a key component for understanding the tropical climate. Since the 1990s, a renewed interest in the role of humidity in climate change triggered a vast amount of analyses that yielded a mature conceptual understanding of the role of water vapor and its functioning in the climate system [see Sherwood et al. (2010b) for a recent update]. First, the well-documented nonlinear relationship between the outgoing longwave radiation and the $\mathrm{RH}$ highlights an enhanced

Corresponding author address: Hélène Brogniez, LATMOS, 11 boulevard d'Alembert, 78280 Guyancourt, France.

E-mail: helene.brogniez@latmos.ipsl.fr contribution of the free-troposphere humidity distribution to the water vapor feedback (Pierrehumbert 1995; Held and Soden 2000). Second, the distribution of RH provides information on the physical parameters at play in the atmosphere (Sherwood et al. 2006, 2010b). In the deep tropics where deep convection frequently occurs, the distribution of upper-tropospheric humidity is close to Gaussian as a result of mixing by deep convection. Over subtropical regions, the last saturation theory (Pierrehumbert and Roca 1998) allows one to explain the lognormal behavior of the probability distribution function observed there (Ryoo et al. 2008). This improved understanding of $\mathrm{RH}$ has been assessed in depth in climate models (Soden et al. 2005; Sherwood et al. 2010a; Hurley and Galewsky 2010; Held and Shell 2012), giving more credit to the latter's representation of the 
processes at play in the water vapor feedback (e.g., Dessler and Sherwood 2009). Most of the satellite observational constraints implied in the elaboration of this model arise from the use of operational and research fleets with strong emphasis on the use of infrared-based instruments. The main limitations of these instruments are their inability to sample the atmosphere when there are clouds and their limited temporal sampling for the climatological descriptions derived from polar-orbiter platforms. This improved understanding of the distribution of $\mathrm{RH}$ also triggered new questions such as the anticipated poleward movement of the subtropical RH minimum and its spatial spread with climate change [see Roca et al. (2011) for a discussion]. The detailed processes of entrainment/detrainment as well as the convective inhibition due to dry tropospheric air in the vicinity of regions of deep convection remain to be explained (Del Genio 2011).

In dry zones and in regions of deep convection, the additional usage of a microwave-based set of observations of the water vapor in the tropical free troposphere can help in analyzing the relationship between deep convection and $\mathrm{RH}$ in the vicinity of rainfall areas at various times of the day. While the operational fleet provides interesting data for such analyses (Buehler et al. 2008; Hong et al. 2008; Chung et al. 2011), the original low-inclination orbit of the Megha-Tropiques mission $\left[20^{\circ}\right.$ around the equator; see Desbois et al. (2003)], together with the Sondeur Atmosphérique du Profil d'Humidité Intertropicale par Radiométrie (SAPHIR) sounding instrument, provides unique observations to address the scientific issues mentioned above.

The Megha-Tropiques satellite was launched on 11 October 2011 from the Sriharikota launch pad in India. It is a collaborative satellite between the French and Indian space agencies [Centre National d'Etudes Spatiales (CNES) and the Indian Space Research Organization (ISRO)] that carries four instruments for the study of the tropical atmospheric water cycle and the associated exchanges of energy: the Microwave Analysis and Detection of Rain and Atmospheric Structures (MADRAS) imager, SAPHIR, the Scanner of Radiation Budget (ScaRaB), and the GPS Radio Occultation Sounder of the Atmosphere (GPS-ROSA; Desbois et al. 2003, 2007). The SAPHIR radiometer (Eymard et al. 2002) is designed to study the vertical distribution of water vapor. It is a cross-track instrument with double sideband modes, whose radiometric main features are recalled in Table 1. SAPHIR scans Earth's atmosphere with a $1700-\mathrm{km}$-wide swath between $30^{\circ} \mathrm{N}$ and $30^{\circ} \mathrm{S}$, a maximum scan angle of $42.96^{\circ}$ (a viewing zenith angle of $\pm 50.7^{\circ}$ ), and a footprint resolution of $10 \mathrm{~km}$ at nadir that distorts to a $14 \mathrm{~km} \times 22 \mathrm{~km}$ ellipse on the edges of
TABLE 1. SAPHIR channel characteristics and radiometric sensitivities [from Karouche et al. (2012)]. For the radiometric sensitivity $\mathrm{Ne} \Delta \mathrm{T}$, the number to the left of the slash is the onground value and the number to the right is the in-orbit value.

\begin{tabular}{|c|c|c|c|}
\hline Channel & $\begin{array}{c}\text { Central } \\
\text { frequency }(\mathrm{GHz})\end{array}$ & Bandwidth (MHz) & $\mathrm{Ne} \Delta \mathrm{T}(\mathrm{K})$ \\
\hline $\mathrm{C} 1$ & $183.31 \pm 0.2$ & 200 & $1.52 / 1.44$ \\
\hline $\mathrm{C} 2$ & $183.31 \pm 1.1$ & 350 & $1.09 / 1.05$ \\
\hline $\mathrm{C} 3$ & $183.31 \pm 2.8$ & 500 & $0.95 / 0.91$ \\
\hline $\mathrm{C} 4$ & $183.31 \pm 4.2$ & 700 & $0.82 / 0.77$ \\
\hline $\mathrm{C} 5$ & $183.31 \pm 6.8$ & 1200 & $0.66 / 0.63$ \\
\hline C6 & $183.31 \pm 11$ & 2000 & $0.56 / 0.54$ \\
\hline
\end{tabular}

the swath. In each scan line, the antenna collects 182 pixels, the so-called L1A data, which are resampled to obtain 130 contiguous pixels, the so-called L1A2 data. The SAPHIR channels are located in the strong absorption band near $183.31 \mathrm{GHz}$ and range from $183.31 \pm$ $0.2(\mathrm{C} 1)$ to $183.31 \pm 11.0 \mathrm{GHz}$ (C6). The first channel sounds the upper layers of the troposphere with a weaker sensitivity because of its narrower bandwidth set by its location in the absorption band. The sixth channel performs a deeper sounding of the atmosphere with the highest sensitivity (Table 1). Early studies on the 183.31-GHz absorption band for $\mathrm{RH}$ profiling (Schaerer and Wilheit 1979; Wang and Chang 1990) have led to designing three-channel sounders [e.g., the Advanced Microwave Sounding Unit-B (AMSU-B); Saunders et al. 1995], and the current six-channel configuration improves the retrievals of $\mathrm{RH}$ (Brogniez et al. 2013; Gohil et al. 2013).

A description of the upper-tropospheric humidity product and its validation against a set of in situ measurements of RH profiles from two campaigns of observations of the tropical atmosphere are presented in this paper. The approach used to retrieve the uppertropospheric humidity (UTH) from SAPHIR is detailed in section 2. The datasets used to evaluate this approach are introduced in section 3 , together with their intrinsic uncertainties and the method used to define the various uncertainties in the evaluation process. The results from this evaluation are presented in section 4 , and scientific questions that could benefit from these estimations are discussed in section 5 .

\section{Algorithm overview}

\section{a. Interpretation of the brightness temperatures}

In the $183-\mathrm{GHz}$ microwave domain, radiation measurements can be expressed as a mean RH value average over a range of pressures in the upper troposphere. This mean RH, or UTH, is estimated from the "water vapor" 
brightness temperature BT on the basis of the theoretical relationship

$$
\ln \mathrm{UTH}=a \mathrm{BT}+b .
$$

Here, BT is corrected for the artificial cooling induced by the satellite viewing angle (the "limb-darkening effect"; e.g., Goldberg et al. 2001). A definition of UTH is provided in the next section. This equation of proportionality between BT and the natural logarithm of UTH requires knowledge of the slope $a$ and the intercept $b$. Equation (1) is derived from simplifications of the radiative transfer theory in water vapor channels and with simple and realistic assumptions about the temperature profile in the tropical atmosphere (Soden and Bretherton 1993; Stephens et al. 1996; Brogniez et al. 2005). This relationship, as such or including additional thermodynamic parameters, has been initially developed for the interpretation of the $6.3-\mu \mathrm{m}$ band of Meteosat-1 (Schmetz and Turpeinen 1988) and GOES-7 (Soden and Bretherton 1993; Chung and Soden 2009). It has been widely applied to similar radiometers such as the High Resolution Infrared Radiation Sounder (HIRS) of the NOAA satellites (Stephens et al. 1996; Jackson and Bates 2001) for long-term studies of the UTH field (see, e.g., Bates et al. 2001; Chung et al. 2011; Gierens et al. 2014), but its estimation is, however, limited to clear-sky and low-level-cloud scenes (Brogniez et al. 2009). Since the water vapor absorption line at $183.31 \mathrm{GHz}$ has the same characteristics as in the infrared (IR), the method has been adapted to measurements at this frequency. The first application was for the $183.31 \pm 1.0-\mathrm{GHz}$ channel of the Special Sensor Microwave Water Vapor Profiler (SSM/T-2) and AMSU-B radiometers with an extension to the nonscattering pixels (Spencer and Braswell 1997; Buehler and John 2005; Brogniez and Pierrehumbert 2006; Buehler et al. 2008). Indeed, clouds that are not composed of precipitating hydrometeors are almost transparent to the radiation emitted in the $183.31-\mathrm{GHz}$ line, which extends the monitoring of the atmospheric water vapor to a large spectrum of cloudy conditions.

\section{b. Definition of the upper-tropospheric humidity}

UTH is a measure of RH (defined with respect to liquid water only) that is vertically averaged over a broad layer of the upper troposphere. The vertical integration includes a weighting by an operator $W$ that is related to the radiation measured by the radiometer and that expresses the transmission of the free troposphere:

$$
\mathrm{UTH}=\frac{\sum_{i} \mathrm{RH}_{i} W_{i}}{\sum_{i} W_{i}} .
$$

From previous studies of the UTH derivation from various channels and spectral regions, the relative humidity Jacobian $J_{\mathrm{RH}}=\Delta \mathrm{BT} / \Delta \mathrm{RH}\left(\mathrm{K}^{-1}\right)$ is selected here as the weighting operator $W$ (Brogniez et al. 2004; Brogniez and Pierrehumbert 2006; Brogniez et al. 2009; Schröder et al. 2014). Other operators are discussed in the literature, such as the specific humidity Jacobian (Buehler et al. 2008) or the classical transmission-based weighting function (Stephens et al. 1996). A comparison between retrievals of UTH that is based on these various weighting operators applied on a common training dataset has highlighted the better adjustment when $J_{\mathrm{RH}}$ is used (Brogniez et al. 2004). Figure 1 summarizes the variation in width and the evolution of the zone of sensitivity of these $J_{\mathrm{RH}}$ according to the type of atmosphere described by the BTs of the three central channels of SAPHIR $(183.31 \pm 0.2, \pm 1.1$, and $\pm 2.8 \mathrm{GHz})$. Here, ECMWF temperature and RH profiles limited to the $30^{\circ} \mathrm{N}-30^{\circ} \mathrm{S}$ area are considered (the " $60 \mathrm{~L}$ profile dataset" of the Satellite Application Facility for Numerical Weather Prediction (http://nwpsaf.eu; Chevallier 2002). As a result of the sampling method used to build this dataset, the 60L-profile dataset has been shown to be suitable for regression purposes (Chevallier et al. 2000; Buehler and John 2005). Version 10 (v10) of the Radiative Transfer for the TIROS Operational Vertical Sounder (RTTOV; see Matricardi et al. 2004) model is used to compute SAPHIR-like BTs as well as the full Jacobian matrices $\left(J_{X}=\partial \mathrm{BT} / \partial X\right.$, where $X$ is any variable atmospheric parameter). By definition, the width and altitude of the peak of $J_{\mathrm{RH}}$ depend on both the absorber amount (via the transmission of the atmosphere) and on the temperature profile. Figure 1 shows that the thickness of the atmospheric layer contributing to the measured radiation varies with the RH distribution: the drier the atmosphere is (i.e., higher BTs), the thicker is the layer. Moreover, the peak of maximum of sensitivity shifts from the upper troposphere ( $\sim 200 \mathrm{hPa}$ at $\pm 0.2 \mathrm{GHz}$ for a $225-\mathrm{K}$ scene) toward the midtroposphere $(500 \mathrm{hPa}$ at $\pm 2.8 \mathrm{GHz}$ for a $280-\mathrm{K}$ scene). Figure 1 further shows that each of the channels exhibits a maximum sensitivity at a different pressure layer; UTH will be distributed accordingly. Hence, channel 1 (C1: $\pm 0.2 \mathrm{GHz}$; Fig. 1a) can be interpreted as the vertically integrated $\mathrm{RH}$ over the 100 500-hPa layer, labeled as UTH1. For channel 2 (C2: $\pm 1.1 \mathrm{GHz}$; Fig. 1b), the layer is just below and covers the 200-600-hPa layer, and the mean RH will be referred to as UTH2. The atmospheric layer covered by channel 3 (C3: $\pm 2.8 \mathrm{GHz}$; Fig. 1c) goes down to $750 \mathrm{hPa}$ and is called UTH3. This results in a vertical description of the free-tropospheric $\mathrm{RH}$, even though the layers slightly overlap. 

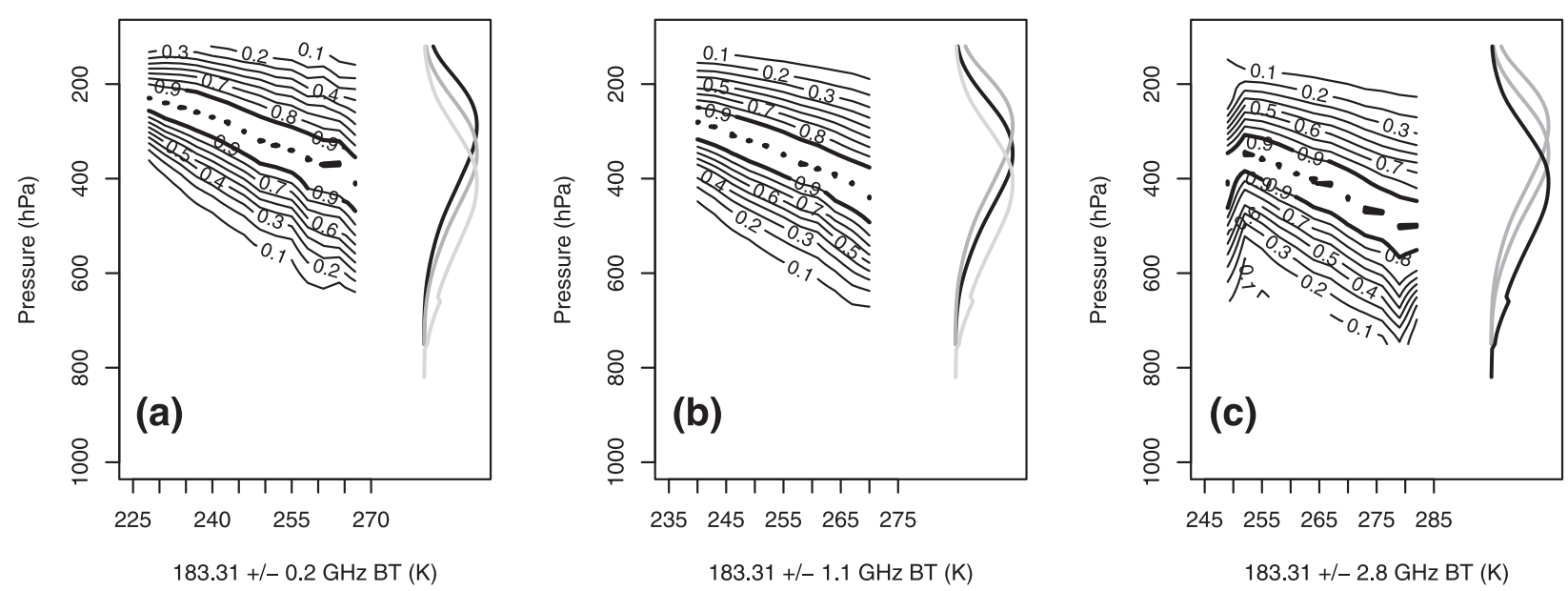

FIG. 1. Distributions of the RH Jacobians $J_{\mathrm{RH}}\left(\mathrm{K} \%^{-1}\right)$, normalized to unity, according to the corresponding BTs $(\mathrm{K})$ of the three central channels of SAPHIR: (a) C1 at $183.31 \pm 0.2 \mathrm{GHz}$, (b) $\mathrm{C} 2$ at $183.31 \pm 1.1 \mathrm{GHz}$, and (c) C3 at $183.31 \pm 2.8 \mathrm{GHz}$. The mean $J_{\mathrm{RH}}$ are also shown on the right-hand side of each panel: the black curve is for the current channel and the gray curve represents the mean $J_{\mathrm{RH}}$ of the other channels, as a reminder. The synthetic SAPHIR BTs and the $J_{\mathrm{RH}}$ are obtained using ECMWF 60L temperature and humidity profiles restricted to the $30^{\circ} \mathrm{N}-30^{\circ} \mathrm{S}$ band and the RTTOV v10 model.

\section{c. Design of the retrievals}

The BT-to-UTH relationship given by Eq. (1) is a global retrieval method (although local methods have been developed; Schmetz and Turpeinen 1988) that requires the computation of the fitting parameters $a$ and $b$ once and for all. This is done through a learning phase using a dataset that is representative of the thermodynamic conditions observed by the radiometer. In this case, this base is built from the ECMWF 60L temperature and moisture profiles mentioned above and the RTTOV v10 model. RTTOV associates each profile with a set of synthetic SAPHIR BTs and their corresponding $J_{\mathrm{RH}}$, which gives three distinct values of UTH following Eq. (2). Hence, a unique couple $(a, b)$ is calculated once and for all from Eq. (1) for each channel $(\mathrm{C} 1, \mathrm{C} 2$, and $\mathrm{C} 3)$ of SAPHIR. The knowledge of the three couples $(a, b)$ allows the interpretation of the BTs measured by $\mathrm{C} 1, \mathrm{C} 2$, and $\mathrm{C} 3$ in terms of UTH1, UTH2, and UTH3 as discussed above. Figure 2 shows the three BT-to-UTH transformations from the ECMWF 60L-profile learning dataset. Each of the regressions explains more than $96 \%$ of the measurements, which underlines the strong water vaporrelated information content in these three observing channels. In the following, UTHs derived from Eq. (1) will be denoted UTH $_{\text {SAPHIR }}$ and the UTH obtained from the vertical average of a $\mathrm{RH}$ profile (be it a model profile or a radiosounding profile) will be denoted $\mathrm{UTH}_{\mathrm{RH}}$.

\section{Data and associated uncertainty estimates}

The radiosounding measurements of two field experiments, considered as the reference dataset, and the
SAPHIR observations interpreted in terms of layeraveraged $\mathrm{RH}$ are presented. The uncertainties that need to be taken into account when comparing two estimates are discussed.

\section{a. Radiosoundings of CINDY/DYNAMO/AMIE 2011 and Ouagadougou 2012}

Two sets of radiosounding (RS) measurements are combined to build a reference dataset that samples various thermodynamic conditions of the tropical atmosphere. The first set is the large sounding dataset produced during the the Cooperative Indian Ocean Experiment on Intraseasonal Variability in the Year 2011/Dynamics of the Madden-Julian Oscillation/ Atmospheric Radiation Measurement Program MaddenJulian Oscillation Investigation Experiment (CINDY/ DYNAMO/AMIE, hereinafter $\mathrm{C} / \mathrm{D} / \mathrm{A}$ ) international field campaign that took place over the Indian Ocean during the 2011/12 boreal winter. The second set consists of profiles obtained from RS launched in Ouagadougou, Burkina Faso $\left(12.36^{\circ} \mathrm{N}, 1.53^{\circ} \mathrm{W}\right)$, during the 2012 summer within the Megha-Tropiques validation campaign.

During the Megha-Tropiques validation campaign, 54 sounding probes were launched from Ouagadougou, in close collaboration with experts from the Agency for Aerial Navigation Safety in Africa and Madagascar (ASECNA) and the Institut de Recherche pour le Développement (IRD). To test the short-term vertical variability of the water vapor field and to further evaluate SAPHIR measurements considering this variability, 27 overpasses of Megha-Tropiques have been sampled with radiosoundings under nonprecipitating conditions to cover a premonsoon period (late May-early June) and 

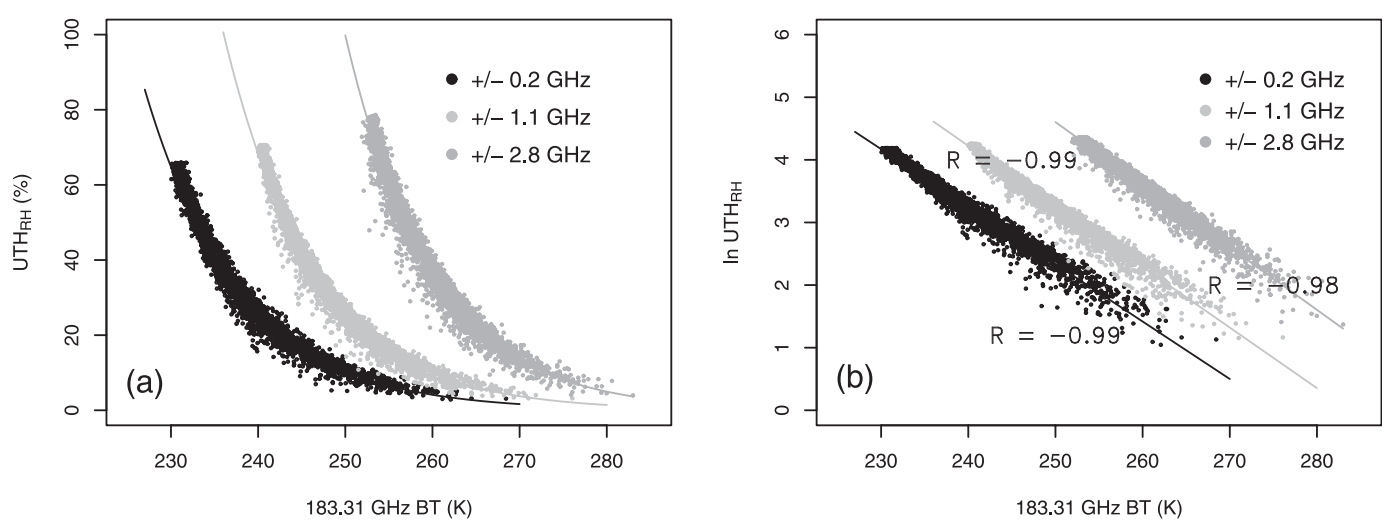

FIG. 2. Scatterplots of the synthetic BTs (K) for channels C1 (black dots), C2 (light gray dots), and C3 (dark gray dots) of SAPHIR vs (a) the associated $\mathrm{UTH}_{\mathrm{RH}}(\%)$ defined from the RH profiles and weighted by the $J_{\mathrm{RH}}$ of the corresponding channel using Eq. (2) and (b) the natural logarithm of $\mathrm{UTH}_{\mathrm{RH}}$. In (b) the lines are the regression fits modeled from Eq. (1). The correlation coefficients are indicated for each regression. The ECMWF profiles of Fig. 1 are used for the computation of the three $\mathrm{UTH}_{\mathrm{RH}}$ as well as for the computation of the synthetic SAPHIR BTs.

a monsoonal period (July). The Vaisala, Inc., "RS92SGPD" probes (hereinafter RS92) have been used for these soundings, which offers consistency with the second set (see below).

The $\mathrm{C} / \mathrm{D} / \mathrm{A}$ campaign was dedicated to investigating the processes involved in the initiation of the MaddenJulian oscillation (MJO). To this end, the campaign collected a large variety of observations (e.g., radar/ mooring networks, microphysics probes, and upper-air measurements). Overall, more than 10000 highresolution soundings have been collected from 51 priority sounding sites (at the time of writing the list could be found online at http://data.eol.ucar.edu/master_list/? project $=$ DYNAMO) with almost 6000 soundings performed with the RS92 system from 12 enhanced sonde sites (Ciesielski et al. 2014). After a restrictive spatiotemporal collocation step with Megha-Tropiques overpasses $(\Delta t< \pm 45 \mathrm{~min}$ around launch time; $\Delta x$ within a $50-\mathrm{km}$ radius) and the screening of diffusive cases associated with precipitation and cold clouds (Greenwald and Christopher 2002; Hong et al. 2005), about 320 radiosoundings from this specific campaign are available to evaluate the SAPHIR estimations.

The common use of the RS92 sounding system for these two sets minimizes discrepancies in data quality and errors in the evaluation process. Numerous studies have characterized the errors and systematic biases of the RS92 probes (Miloshevich et al. 2004, 2009; Vömel et al. 2007; Nash et al. 2011). For instance, the Global Climate Observing System (GCOS) Reference UpperAir Network (GRUAN; Seidel et al. 2009) has focused on RS92 sites to establish a reference-quality network of vertical profiles of temperature and humidity to provide high-quality climate records that can be used to detect and monitor global and regional signals of climate change (GCOS 2013). GRUAN puts a strong emphasis on the calibration of the probes, on the description of their errors (random or systematic), and on the correction of their errors using specific methods (Immler et al. 2010; Dirksen et al. 2014). The data from the Ouagadougou 2012 experiment and a subset of the $\mathrm{C} / \mathrm{D} / \mathrm{A}$ soundings have been processed using the GRUAN correction method. The remaining C/D/A RH profiles used here underwent a National Center for Atmospheric Research (NCAR) correction scheme dedicated to the radiation bias (Wang et al. 2013). After quality control of the profiles and correction of the known biases, the residual errors are due to the manufacturing of the sensor and its ground-based calibration [see Clain et al. (2014) for more details on the processing steps]. The residual errors are evaluated by Miloshevich et al. (2009) in two ways. One ways looks at a random variability of the sensor production that is related to humidity conditions, ranging over $\pm 1.5 \%$ of the measured $\mathrm{RH}$ for $\mathrm{RH}>10 \%$ and over $\pm 3 \%$ of the measured $\mathrm{RH}$ for $\mathrm{RH}<10 \%$, expressed as

$$
\varepsilon_{1}=\left\{\begin{array}{l}
0.015 \times \mathrm{RH} \quad \text { if } \quad \mathrm{RH}>10 \% \\
0.03 \times \mathrm{RH} \text { if } \mathrm{RH}<10 \%
\end{array} .\right.
$$

The second considers a residual uncertainty bias that accounts for both the sensor variability and the groundcheck-calibration variability and that differs between daytime ( $\pm 5 \%$ of the measured $\mathrm{RH} \pm 0.5 \% \mathrm{RH}$ offset $)$ and nighttime ( $\pm 4 \%$ of the measured $\mathrm{RH} \pm 0.5 \% \mathrm{RH}$ offset):

$$
\varepsilon_{2}= \pm\left\{\begin{array}{l}
0.05 \times \mathrm{RH}+0.5 \text { daytime uncertainty } \\
0.04 \times \mathrm{RH}+0.5 \text { nighttime uncertainty }
\end{array} .\right.
$$

The three channels that are considered are not sensitive to the surface emissivity. As a result, no 
distinction between continental and oceanic conditions is made.

The integrated UTH uncertainty, which is defined from the RS relative humidity and is denoted as $\Delta \mathrm{UTH}_{\mathrm{RH}}$, can be computed using the Jacobian $J_{\mathrm{RH}}$ to weight the overall profile of uncertainties:

$$
\Delta \mathrm{UTH}_{\mathrm{RH}}=\frac{\sum_{i} \varepsilon_{\mathrm{RS}}^{i} J_{\mathrm{RH}}^{i}}{\sum_{i} J_{\mathrm{RH}}},
$$

where $\varepsilon_{\mathrm{RS}}^{i}$ is obtained for each pressure level $i$ considering the two known intrinsic errors of the Vaisala RS92 system listed above. The $\varepsilon_{\mathrm{RS}}^{i}$ is given by

$$
\varepsilon_{\mathrm{RS}}^{i}=\left[\left(\varepsilon_{1}^{i}\right)^{2}+\left(\varepsilon_{2}^{i}\right)\right]^{1 / 2} .
$$

The inaccuracies in the computation of the Jacobian $J_{\mathrm{RH}}$ provided by RTTOV also contribute to the global uncertainty of $\mathrm{UTH}_{\mathrm{RH}}$ because it is used to weight the RH profile [Eq. (2)]. An evaluation of the water vapor Jacobians computed by fast radiative transfer models (such as RTTOV) has been performed by Chen et al. (2010). It was shown that the forward model itself and the $\mathbf{K}$-matrix model containing the Jacobian could cause the inaccuracies in the computation of the Jacobians. RTTOV is a fast model that fits a line-by-line (LBL) generated transmittance at fixed pressure levels. For the microwave spectrum, the LBL model is the MillimeterWave Propagation Model (MPM-89/92; Saunders et al. 1999) and the forward computations of the BTs have biases that are less than $0.1 \mathrm{~K}$ with respect to the LBL MPM for all of the Microwave Humidity Sounder (MHS) channels. A measure of the goodness of fit of the water vapor Jacobians also indicates an excellent fit for most of the atmospheric profiles tested (e.g., no unphysical oscillations or noise). The measure of goodness of fit is, however, a summation over the entire profile (Garand et al. 2001) and is only indicative. No quantitative value can be associated with the accuracy of the Jacobians over the atmospheric layers considered in the definition of the UTHs. Therefore, the overall error model does not include terms that are related to the computation of the $J_{\mathrm{RH}}$.

\section{b. SAPHIR data}

The onboard calibration of SAPHIR is monitored by CNES and ISRO. Karouche et al. (2012) have shown the high stability of the internal hot load $(\Delta T<1.5 \mathrm{~K})$. To complement the monitoring performed by the space agencies, Clain et al. (2014) discussed the evaluation of the observations using the same tools as here (i.e., the $\mathrm{C} / \mathrm{D} / \mathrm{A}$ set of RS and the RTTOV v10 model). Observations from
TABLE 2. Correlation coefficients, slopes, and intercepts of the linear fits between synthetic BTs from RS (CINDY/DYNAMO/ AMIE Vaisala RS92 probes-day and night) and the collocated SAPHIR observations within 25 pixels around the launch site, for the six channels of SAPHIR. [Adapted from Clain et al. (2014).]

\begin{tabular}{lccccc}
\hline \hline Channel & $R$ & Bias (K) & $\begin{array}{c}\text { Total } \\
\text { uncertainty } \varepsilon(\mathrm{K})\end{array}$ & Slope & $\begin{array}{c}\text { Intercept } \\
(\mathrm{K})\end{array}$ \\
\hline C1 (UTH1) & 0.93 & 0.19 & 2.55 & 1.04 & -9.89 \\
C2 (UTH2) & 0.97 & 0.75 & 2.17 & 1.04 & -9.21 \\
C3 (UTH3) & 0.98 & 1.30 & 1.79 & 0.97 & 10.1 \\
C4 & 0.98 & 1.59 & 1.62 & 0.94 & 16.4 \\
C5 & 0.98 & 1.53 & 1.50 & 0.93 & 21.6 \\
C6 & 0.97 & 2.31 & 1.41 & 0.88 & 35.4 \\
\hline
\end{tabular}

the six channels are compared with the simulated BTs from the RS RH and temperature profiles, with different sources of surface emissivities: 1 ) over the oceans, the Fast Emissivity Model (FASTEM-4; English and Hewison 1998) implemented in RTTOV is used with the 10-m wind speed from the RS and, 2) over the continents, collocated emissivities from the atlas of Prigent et al. (2006) built from $10 \mathrm{yr}$ of Special Sensor Microwave Imager (SSM/I) observations are extracted. Clain et al. (2014) have extensively discussed the methodological uncertainties such as those affecting the radiative transfer calculations (e.g., the impact of ozone), the sampling errors induced by the spatiotemporal collocation, and the known uncertainties of the RS92 probe. The main results are summarized in Table 2, with mean biases and standard deviations given for each of the six channels. A positive bias (RS - SAPHIR) from the central channel $(\mathrm{C} 1)$ to the wing channel (C6) is observable. This pattern is also featured on the similar channels of MHS on MetOp-A (V. Payne 2013, personal communication) and remains to be explained. Considering the total uncertainty, the biases of the three channels $\mathrm{C} 1, \mathrm{C} 2$, and $\mathrm{C} 3$ that are used here for the estimation of UTHs are within the instrumental specifications. Empirical correction coefficients have been obtained from this study and are indicated in Table 2. These coefficients are used to correct the L1A2 BTs before their conversion into UTHs.

Even though the BT-to-UTH retrieval is derived from theoretical statements on the radiative transfer equation in a strong absorption band [see Soden and Bretherton (1993) for the underlying assumptions], the estimation of the regression coefficients (denoted as $\hat{a}$ and $\hat{b}$ ) is done by a learning phase (see section $2 \mathrm{c}$ ), and the accuracy of these estimates will depend on the learning dataset. Let $\delta a$ and $\delta b$ be the uncertainties associated with $\hat{a}$ and $\hat{b}$, respectively. It is important to propagate these uncertainties in the satellite measurements (denoted as $\delta \mathrm{BT}$ in the following). These uncertainties are 

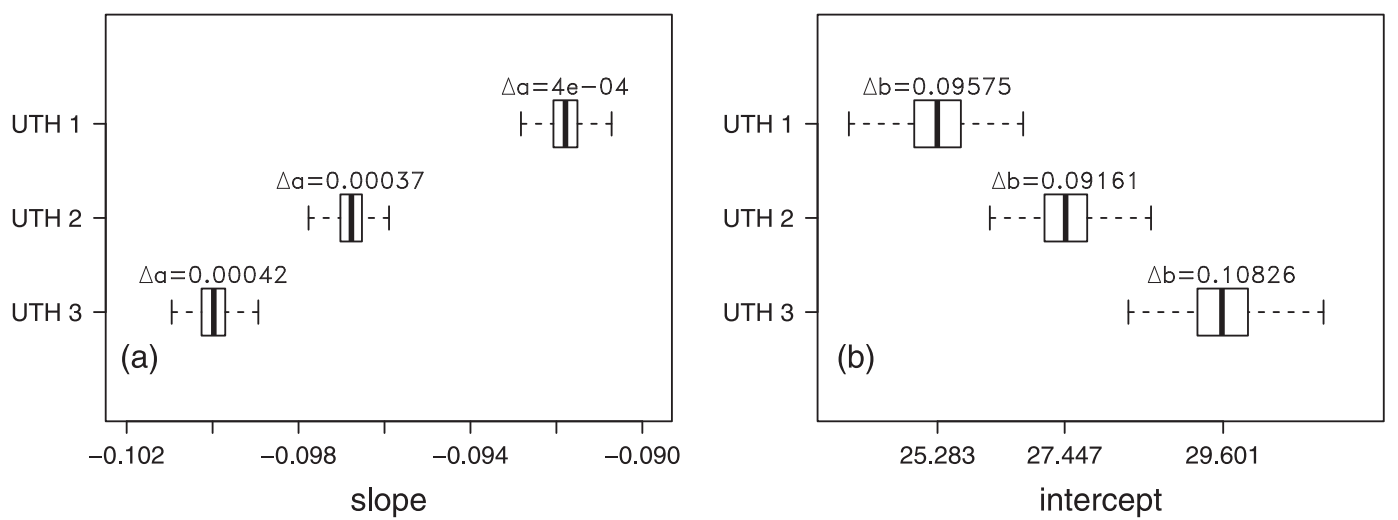

FIG. 3. Box-and-whiskers diagrams of (a) the slope $a\left(\mathrm{~K}^{-1}\right)$ and (b) the intercept $b$ for the BT-to-UTH relationship designed for each of the three channels (UTH1, UTH2, and UTH3). The diagrams feature the median (the central vertical line) and the lower and upper quartiles of the distributions (left and right edges of the boxes). The whiskers give the lower and upper limits of the distributions. These limits are defined within 1.5 times the interquartile range computed from the lower and upper quartiles of the distributions. The widths of the $68 \%$ confidence intervals are indicated. The lowercase e indicates 10 raised to the number following it.

provided as the noise equivalent temperature $(\mathrm{Ne} \Delta \mathrm{T})$ in Table 1. The $\mathrm{Ne} \Delta \mathrm{T}$ gives the minimum temperature variation detected by the receiver. It is a function of the noise in the system: a large bandwidth (among other factors) yields a small $\mathrm{Ne} \Delta \mathrm{T}$ (Saunders et al. 1995). Taking these uncertainties into account in the estimation of UTH would strengthen the comparison with RS measurements. The propagation of uncertainties through nonlinear regression models is a complex issue, however, that assumes that the uncertainties are independent. A way to avoid this problem is to assume a possible dependency between the parameters, which is the case here. The linearization of the problem leads to a maximization of the uncertainty in UTH $(\delta \mathrm{UTH})$, as follows:

$$
\delta \mathrm{UTH} \leq\left|\frac{\partial f}{\partial \mathrm{BT}}\right| \delta \mathrm{BT}+\left|\frac{\partial f}{\partial a}\right| \delta a+\left|\frac{\partial f}{\partial b}\right| \delta b,
$$

where $f$ is the regression model [i.e., Eq. (1)]. A reasonable assumption consists of approximating the uncertainties $\delta x$ of the parameter $x$ by its standard deviation, hereinafter $\Delta x$. Equation (3) thus may be rewritten as

$$
\frac{\Delta \mathrm{UTH}_{\mathrm{SAPHIR}}}{\mathrm{UTH}_{\mathrm{SAPHIR}}} \leq \hat{a} \times \Delta \mathrm{BT}+\Delta a \times \mathrm{BT}+\Delta b,
$$

where $\mathrm{UTH}_{\text {SAPHIR }}$ refers to the estimate of UTH from SAPHIR measurements. For each of the three channels, $\triangle \mathrm{BT}$ is defined from the evaluation of the SAPHIR BTs whose main results are described in section $2 b$. The uncertainties $\Delta a$ and $\Delta b$ are obtained using a bootstrap method (random resampling with replacement) that also allows the testing of the robustness of the relationship. Figures $3 a$ and $3 b$ summarize the results of the bootstrap method using box-and-whiskers diagrams to represent the distributions of the regression coefficients $\hat{a}$ and $\hat{b}$. The boxes are symmetric around the medians, and the whiskers, representing the spread of the distributions, are of the same length. This result suggests that the distributions are very close to the Gaussian distribution, yielding to define $\Delta a$ and $\Delta b$ as the $68 \%$ confidence intervals of the distributions.

\section{Results of the evaluation}

\section{a. Methodological aspects}

The comparison between the satellite UTHs and the in situ estimates from the RS are performed following the method of Roca et al. (2010). This method evaluates satellite rainfall estimates with a detailed definition of the uncertainties associated with the ground estimate of rainfall accumulation measured by rain gauges and the uncertainties associated with the satellite products (mainly sampling issues). As in Roca et al. (2010), the approach of Kelly (2007) was applied: for two variables $x_{i}$ and $y_{i}$ with known uncertainties $\varepsilon_{x}^{i}$ and $\varepsilon_{y}^{i}$ that are both normally distributed, with respective variances $S_{x}^{i}$ and $S_{y}^{i}$, then the regression relationship between vectors $\mathbf{x}$ and $\mathbf{y}$ can be written as

$$
y_{i}+\varepsilon_{y}^{i}=\alpha+\beta\left(x_{i}+\varepsilon_{x}^{i}\right)+\varepsilon^{i},
$$

where $\varepsilon^{i}$ is a random variable that represents the intrinsic scatter at $i$ about the regression relationship and $\alpha$ and $\beta$ are the regression coefficients. As underlined by 
UTH 1 : channel $183.31+/-0.2 \mathrm{GHz}$
UTH 2 : channel $183.31+/-1.1 \mathrm{GHz}$
UTH 3 :

channel $183.31+/-2.8 \mathrm{GHz}$
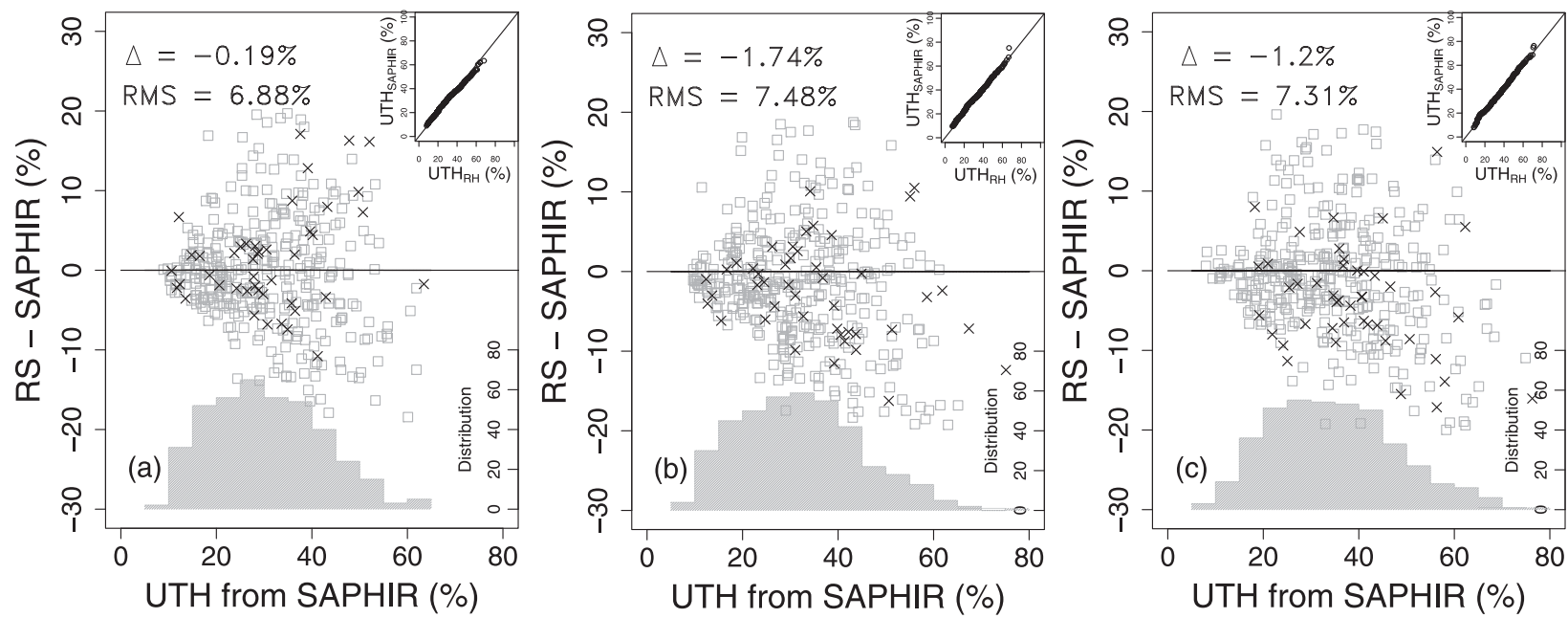

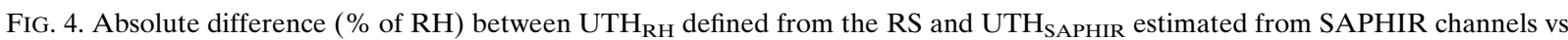
$\mathrm{UTH}_{\text {SAPHIR }}$ for (a) UTH1, (b) UTH2, and (c) UTH3. The black times signs indicate Ouagadougou RS, and the open gray squares indicate C/D/A RS. For each channel, the biases and RMS errorss are given as well as the frequency distribution of the data with gray histograms. The top-right insets represent quantile-quantile plots of $\mathrm{UTH}_{\mathrm{RH}}$ and $\mathrm{UTH}_{\mathrm{SAPHIR}}$.

Kelly (2007), uncertainties in measurements of variables have a spurious increasing/decreasing effect on the correlation between two variables, and its magnitude will depend on the value of the uncertainties with respect to the observed variances in $\mathbf{x}$ and $\mathbf{y}$.

A Bayesian method is used to solve the linear regression between vectors $\mathbf{x}$ and $\mathbf{y}$, accounting for the uncertainties using the computation of the maximumlikelihood function of the data. A full description of the underlying assumptions can be found in Kelly (2007). Here, we therefore assume that the uncertainties of both the SAPHIR $\left(\varepsilon_{x}^{i}=\Delta \mathrm{UTH}_{\mathrm{SAPHIR}}\right)$ and the RS $\left(\varepsilon_{y}^{i}=\Delta \mathrm{UTH}_{\mathrm{RH}}\right)$ measurements have a Gaussian distribution.

\section{b. Results}

\section{1) StANDARD EVAluation}

Figure 4 shows the absolute differences between $\mathrm{UTH}_{\mathrm{SAPHIR}}$ and $\mathrm{UTH}_{\mathrm{RH}}$ for the three UTHs, as well as the mean biases, the RMS, and the frequency distribution of $\mathrm{UTH}_{\mathrm{SAPHIR}}$. The correlation coefficients are $0.85,0.84$, and 0.86 , respectively, for UTH1, UTH2, and UTH3. The quantile-quantile plots provided for each channel reveal that the distributions of $\mathrm{UTH}_{\mathrm{SAPHIR}}$ and $\mathrm{UTH}_{\mathrm{RH}}$ are overall very consistent. The three retrievals are characterized by small negative biases between $-1.74 \%$ of RH (UTH2) and $-0.19 \%$ of RH (UTH1) and by RMS values lower than $8 \%$ in $\mathrm{RH}$ units, highlighting the globally weak scatter of the data. The distinction between the two sets of RS (Ouagadougou and $\mathrm{C} / \mathrm{D} / \mathrm{A}$ ), highlighted in the figures with different symbols, does not show a dependency on the location, which can be interpreted in terms of weather conditions: premonsoon and monsoonal continental conditions for the Ouagadougou subset and mainly oceanic conditions linked to MJO situations for the $\mathrm{C} / \mathrm{D} / \mathrm{A}$ subset. A daytime/nighttime separation is done on the full set of RS: RS launches performed between 1800 and 0600 LT are considered to be nighttime profiles. The means, standard deviations, and correlation coefficients of the UTHs are listed in Table 3 and include the daytime/ nighttime separation. A one-sample $t$ test was applied to test whether the biases are significantly different from 0 , considering the sizes of the datasets. The $p$ values of the $t$ tests are also given in Table 3, and a value lower than 0.05 (i.e., at the $95 \%$ confidence interval) will reject the null hypothesis defined as bias equal to 0 . Table 3 shows that there is no clear influence of time of day on the overall statistics, although the biases of UTH1 are of opposite signs between the daytime subset $(0.74 \%$ of $\mathrm{RH})$ and the nighttime subset $(-1.57 \%$ of $\mathrm{RH})$. This is due to a very slight shift of the barycenter of the scatter.

Channel $\mathrm{C} 1$ of SAPHIR is unique among the existing microwave sounders, and therefore the results obtained for UTH1 cannot be evaluated by using other studies. Moreover, to our knowledge, no estimation of UTH 
TABLE 3. Statistical elements of the absolute comparison between $\mathrm{UTH}_{\mathrm{RH}}$ estimated from the RS profiles and the collocated $\mathrm{UTH}_{\mathrm{SAPHIR}}$ : means, standard deviations $\sigma$, correlation coefficients, and $p$ values from a Student's $t$ test. The $p$ values should be lower than 0.05 (the $95 \%$ confidence interval) to reject the null hypothesis (difference is equal to 0 ). The full dataset is also shared into two subsets: a daytime set and a nighttime set.

\begin{tabular}{lccc}
\hline \hline & $\mathrm{UTH} 1$ & $\mathrm{UTH} 2$ & $\mathrm{UTH} 3$ \\
\hline \multicolumn{3}{c}{ Full set (403 points) } \\
Bias (\%) & -0.19 & -1.73 & 1.20 \\
$\sigma(\%)$ & 6.88 & 7.28 & 7.21 \\
$R$ & 0.85 & 0.85 & 0.86 \\
$p$ value & 0.571 & $2.34 \times 10^{-6}$ & $8.8 \times 10^{-4}$ \\
& & Day $(240$ points $)$ & \\
Bias $(\%)$ & 0.74 & -1.12 & -1.06 \\
$\sigma(\%)$ & 7.06 & 7.40 & 7.17 \\
$R$ & 0.86 & 0.85 & 0.86 \\
$p$ value & 0.104 & 0.019 & 0.023 \\
& & Night $(163$ points $)$ & \\
Bias $(\%)$ & -1.57 & -2.64 & -1.42 \\
$\sigma(\%)$ & 6.37 & 7.02 & 7.29 \\
$R$ & 0.84 & 0.83 & 0.85 \\
$p$ value & 0.002 & $3.45 \times 10^{-6}$ & 0.014 \\
\hline
\end{tabular}

from the $183.31 \pm 3.0-\mathrm{GHz}$ channels of AMSU-B and MHS has been performed yet, and the work that is presented here clearly shows the possibility of doing so with the very similar channel C3 of SAPHIR. Therefore, only the results obtained for UTH2 (for C2 at $183.31 \pm$ $1.1 \mathrm{GHz}$ ) can be compared with the existing studies on UTH as estimated from other operational radiometers. For instance, Buehler et al. (2008) found site-dependent $\mathrm{RH}$ differences ranging between $-5 \%$ and $+5 \%$ when comparing the estimation of UTH from the $183.31 \pm$ 1.0-GHz channel of AMSU-B on board NOAA-15-17 with RS measurements from several sites, whereas Brogniez et al. (2009), who exploited the 6.3- $\mu \mathrm{m}$ channel of the Meteosat Visible and Infrared Imager (MVIRI) on board Meteosat-2-7 (1984-2005) to estimate the freetropospheric humidity, found a mean bias of $-1.2 \%$ of $\mathrm{RH}$ over the period with respect to an RS set. The recent extension of the latter work to the Spinning Enhanced Visible and Infrared Imager (SEVIRI) of Meteosat Second Generation (Schröder et al. 2014) supports this bias value. The UTH retrieval method is very simple in comparison with the complexity of statistical models or physically constrained approaches required to estimate an RH profile (Wilheit 1990; Cabrera-Mercader and Staelin 1995; Sivira et al. 2015). Therefore, the overall quality of the estimation of these UTHs gives some additional insight into the vertical distribution of the $\mathrm{RH}$, even though no precise attribution of vertical pressure domains can be made.

\section{2) ACCOUNTING FOR THE MEASUREMENT UNCERTAINTIES}

The evaluation of the UTHs is now discussed with respect to the regression lines characterized by their slope $\alpha$ and their intercept $\beta$ :

- the bias of the regression $\Delta=\beta+\overline{\mathrm{UTH}_{\mathrm{RH}}}(\alpha-1)$, with $\overline{\mathrm{UTH}_{\mathrm{RH}}}$ referring to the mean value of $\mathrm{UTH}_{\mathrm{RH}}$, and

- the root-mean-square of the regression RMS = $\left(1-R^{2}\right)^{1 / 2} \times\left(S_{\text {SAPHIR }}\right)^{1 / 2}$, with $S_{\text {SAPHIR }}$ referring to the variance of $\mathrm{UTH}_{\mathrm{SAPHIR}}$ and $R$ being the correlation coefficient.

The $\Delta$ and RMS of the regressions defined with ("err" subscript) and without ("std" subscript), the latter taking into account the individual uncertainties, are computed for comparison purposes. Figure 5 shows the scatterplots of $\mathrm{UTH}_{\mathrm{SAPHIR}}$ versus $\mathrm{UTH}_{\mathrm{RH}}$ with a representation of the uncertainties in both estimates (bars). Overall, the RMS is reduced when accounting for the individual uncertainties while, as expected, the $\Delta$ do not change much. The uncertainty bars associated with $\mathrm{UTH}_{\text {SAPHIR }}$ for UTH1 are slightly larger than for UTH2 and $\mathrm{UTH} 3$. This is due to the larger radiometric noise $\mathrm{C} 1$ relative to the that of $\mathrm{C} 2$ and $\mathrm{C} 3$. This impacts the regression accounting for the errors (dashed line), which is more distant from the $y=x$ line than the standard regression (dashed-dotted line), with a slightly larger $\Delta$ $\left(\Delta_{\text {std }}=1.57 \%\right.$ of RH vs $\Delta_{\text {err }}=3.12 \%$ of RH). Despite this feature of the UTH1 scatterplot, the agreement between $\mathrm{UTH}_{\mathrm{SAPHIR}}$ and $\mathrm{UTH}_{\mathrm{RH}}$ is good for the three levels, with centered distributions around small $\Delta_{\mathrm{err}}$ : $3.12 \%$ of RH for UTH $1,-3.58 \%$ of RH for UTH 2 , and $-2.22 \%$ of RH for UTH3. The RMS err $_{\text {RH values are }}$ below $5 \%(0.92 \%, 4.71 \%$, and $4.68 \%$ of $\mathrm{RH}$, respectively, for UTH1-3), with overall correlation coefficients of greater than 0.93 , which gives good confidence in our approach for estimating the tropical UTH from SAPHIR channels.

\section{Conclusions and outlook}

Upper-tropospheric humidity can be estimated from SAPHIR measurements in three specific channels $(\mathrm{C} 1$ at $\pm 0.2, \mathrm{C} 2$ at \pm 1.1 , and $\mathrm{C} 3$ at $\pm 2.8 \mathrm{GHz}$ around the 183.31-GHz water vapor absorption band) by using a method that was developed from $6.3-\mu \mathrm{m}$ measurements (Soden and Bretherton 1993) and is well suited for $183.31 \pm 1.0-\mathrm{GHz}$ observations (Spencer and Braswell 1997). The definition of these three UTHs has been discussed using the relative humidity Jacobians to interpret the measured radiation (Brogniez et al. 2004, 

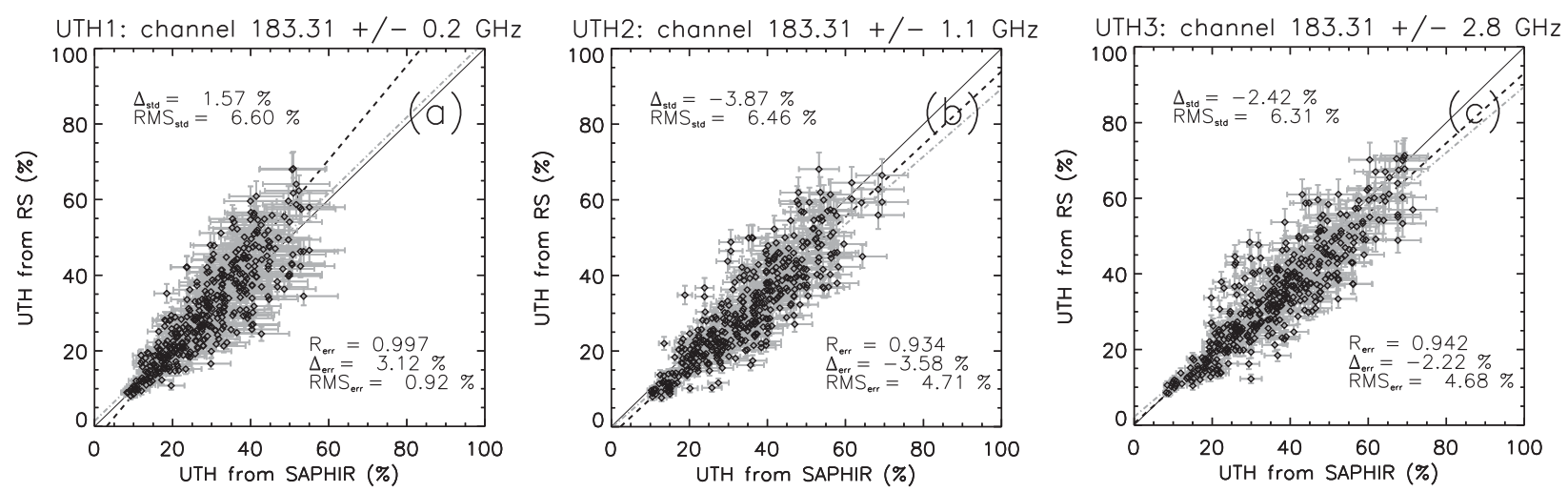

FIG. 5. Scatterplots of the UTHs (\%) derived from SAPHIR BTs vs UTHs defined from the $J_{\mathrm{RH}}$-weighted RH profiles of the C/D/A and Ouagadougou soundings: (a) UTH1, (b) UTH2, and (c) UTH3. Error bars related to the measured RH profile (vertical) and to the SAPHIR BT-to-UTH retrieval (horizontal) are shown in gray. The gray dashed-dotted line is the standard regression line, and the black dashed line is the regression line accounting for errors. The mean bias $\Delta$ and RMS of the regression and the correlation coefficient $R$ are indicated with the "err" subscript, and the $y=x$ line is shown in gray.

2009) and to give a vertical distribution of humidity. UTH1 (from C1) provides information on a layer covering $100-500 \mathrm{hPa}, \mathrm{UTH} 2$ (from $\mathrm{C} 2$ ) is just below and covers the 200-600-hPa layer, and UTH3 (from C3) goes down to $750 \mathrm{hPa}$. These three UTHs give an overall view of the free-tropospheric $\mathrm{RH}$ with a vertical structure. These datasets are made available to the international scientific community by the French ground segment of the Megha-Tropiques mission [the Cloud-AerosolWater-Radiation Interactions (ICARE) Center; http:// www.icare.univ-lille1.fr/mt].

Two sets of tropical soundings for measurements of RH profiles, on which stringent quality control has been performed, are used to evaluate UTH derived from SAPHIR measurements. An additional analysis of the uncertainties on both the satellite retrieval and the RS data has been performed to better characterize the evaluation of UTH. The agreement between the SAPHIR UTHs and the RS UTHs is good. The absolute biases are lower than $2 \%$ of $\mathrm{RH}$ and the RMS are small for the three retrievals, which is comparable to the existing sets of UTH estimated from other radiometers in the microwave and in the infrared.

This in-depth analysis of the uncertainties associated with the two datasets that are compared with each other does not assess the intrinsic difference between the nearly instantaneous satellite observations (one scan of SAPHIR lasts less than $2 \mathrm{~s}$ ) and the vertical sampling of the atmosphere (it takes typically about $1.5 \mathrm{~h}$ for a sounding system to reach a height of $20-25 \mathrm{~km}$ ). These two systems therefore give different points of view of the state of the atmosphere, and further work is needed to better assess the proportion of such methodological noise in the overall error budget. The set of RS collected over Ouagadougou during the 2012 summer (see section 3a) will be analyzed to estimate such methodological noise. The initial strategy of the Ouagadougou 2012 RS campaign was indeed to launch two RS for each selected overpass with a delay: the first one being launched $45 \mathrm{~min}$ before the overpass of Megha-Tropiques and the second one being launched only $15 \mathrm{~min}$ before the very same overpass so as to sample two parts of the atmospheric column.

Insight into the UTHs as seen by SAPHIR is provided in Fig. 6, where three successive overpasses over West Africa $\left(10^{\circ}-20^{\circ} \mathrm{N}, 10^{\circ} \mathrm{W}-0^{\circ}\right.$; the Ouagadougou region) are sampling a mesoscale convective system (MCS), crossing Burkina Faso on 18 August 2012 every 100 min. An asymmetry around the system is clearly seen, with a dry troposphere northwest of the MCS and a progressive moistening of the troposphere on its eastern part. Water vapor plumes are visible around the system. They are presumably produced by convective detrainment, and they seem to dissipate over the successive overpasses as the system moves westward. The exploitation of the UTH data should benefit, for instance, characterization of the vertical distribution of humidity ahead and behind MCSs along their life cycle. In a more general sense, this recently available new dataset should be helpful for investigating climate variability in the tropical region.

Acknowledgments. The authors are thankful to Christophe Dufour (LATMOS) and to the ICARE Data and Service Center for their work on the UTH scientific algorithm and for its maintenance. The French scientific level-2 products derived from the SAPHIR and $\mathrm{ScaRaB}$ instruments have been released in October of 2013. These products include the upper-tropospheric humidity. They are made available to the international 

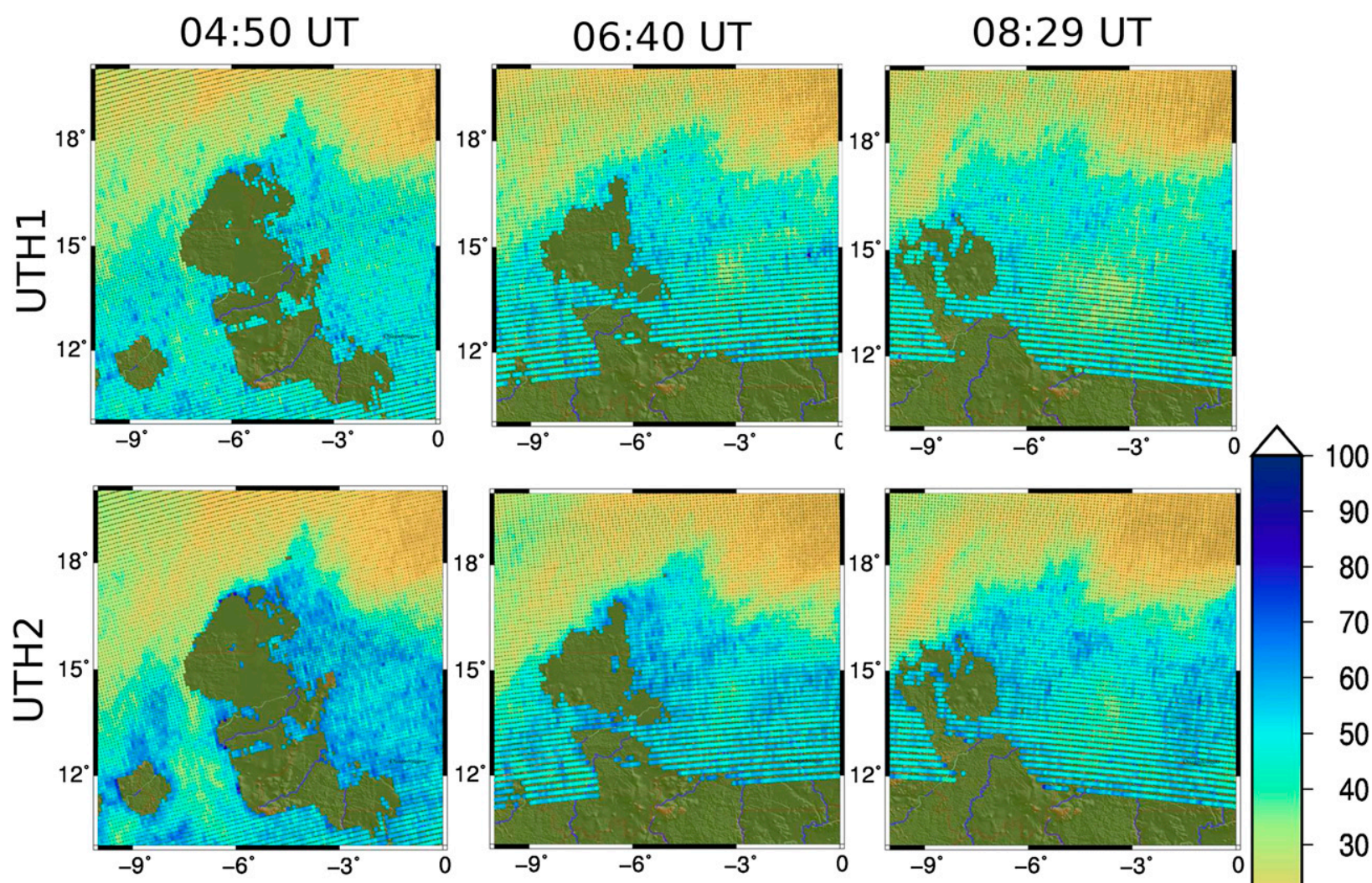

scientific community by the French ground segment (the ICARE Center; http://www.icare.univ-lille1.fr/mt). Help from Michael Sommer, from the GRUAN Lead Centre (Lindenberg Meteorological Observatory of the Deutscher Wetterdienst), with processing of the Ouagadougou Vaisala RS92 measurements was greatly appreciated. The help and insights of R. Johnson, P. Ciesielski (Colorado State University), and J. Wang (NCAR) on the CINDY/DYNAMO/AMIE radiosounding dataset are also appreciated. We also thank B. Kelly for making his IDL fitting routine available. The support of K. Ramage and S. Bouffiès-Cloché and the IPSL data server "Climserv" was also appreciated. Audine Laurian and the two anonymous reviewers are thanked for their suggestions and comments on the manuscript.

\section{REFERENCES}

Bates, J. J., D. L. Jackson, F.-M. Bréon, and Z. D. Bergen, 2001: Variability of tropical upper tropospheric humidity 19791998. J. Geophys. Res., 106, 32271-32 281, doi:10.1029/ 2001JD000347.

Brogniez, H., and R. T. Pierrehumbert, 2006: Using microwave observations to assess large-scale control of the free tropospheric 
water vapor in the mid-latitudes. Geophys. Res. Lett., 33, L14801, doi:10.1029/2006GL026240.

—, L. Picon, and R. Roca, 2004: Interannual and intraseasonal variabilities of the free tropospheric humidity using Meteosat water vapor channel channel over the tropics. Proc. EUMETSAT Meteorological Satellite Conf., Prague, Czech Republic, EUMETSAT. [Available online at http://brogniez.page.latmos. ipsl.fr/docs/proceeding_Eumetsat2004.pdf.]

-, R. Roca, and L. Picon, 2005: Evaluation of the distribution of subtropical free tropospheric humidity in AMIP-2 simulations using METEOSAT water vapor channel data. Geophys. Res. Lett., 32, L19708, doi:10.1029/2005GL024341.

- - , and 2009: A study of the free tropospheric humidity interannual variability using METEOSAT data and an advection-condensation transport model. J. Climate, 22, 6773-6787, doi:10.1175/2009JCLI2963.1.

_ , P.-E. Kirstetter, and L. Eymard, 2013: Expected improvements in the atmospheric humidity profile retrieval using the Megha-Tropiques microwave payload. Quart. J. Roy. Meteor. Soc., 139, 842-851, doi:10.1002/qj.1869.

Buehler, S. A., and V. O. John, 2005: A simple method to relate microwave radiances to upper tropospheric humidity. J. Geophys. Res., 110, D02110, doi:10.1029/2004JD005111.

-, M. Kuvatov, V. O. John, M. Milz, B. J. Soden, D. L. Jackson, and J. Notholt, 2008: An upper tropospheric humidity data set from operational satellite microwave data. J. Geophys. Res., 113, D14110, doi:10.1029/2007JD009314.

Cabrera-Mercader, C. R., and D. H. Staelin, 1995: Passive microwave relative humidity retrievals using feedforward neural networks. IEEE Trans. Geosci. Remote Sens., 33, 1324-1328, doi:10.1109/36.477189.

Chen, Y., Y. Han, P. van Delst, and F. Weng, 2010: On water vapor Jacobian in fast radiative transfer model. J. Geophys. Res., 115, D12303, doi:10.1029/2009JD013379.

Chevallier, F., 2002: Sampled databases of 60-level atmospheric profiles from the ECMWF analysis. EUMETSAT SAF Program Research Rep. NWPSAF-EC-TR-004, 27 pp.

—, A. Chédin, F. Chéruy, and J.-J. Morcrette, 2000: TIGR-like atmospheric-profile databases for accurate radiative-flux computation. Quart. J. Roy. Meteor. Soc., 126, 777-785, doi:10.1002/ qj. 49712656319.

Chung, E.-S., and B. J. Soden, 2009: A satellite-based assessment of upper-tropospheric water vapor measurements during AFWEX. J. Appl. Meteor. Climatol., 48, 2284-2294, doi:10.1175/ 2009JAMC2250.1.

_, — B.-J. Sohn, and J. Schmetz, 2011: Model-simulated humidity bias in the upper troposphere and its relation to the largescale circulation. J. Geophys. Res., 116, D10110, doi:10.1029/ 2011JD015609.

Ciesielski, P. E., and Coauthors, 2014: Quality-controlled upper-air sounding dataset for DYNAMO/CINDY/AMIE: Development and corrections. J. Atmos. Oceanic Technol., 31, 741764, doi:10.1175/JTECH-D-13-00165.1.

Clain, G., H. Brogniez, V. H. Payne, V. O. John, and M. Luo, 2014: An assessment of SAPHIR calibration using high quality tropical soundings. J. Atmos. Oceanic Technol., 32, 61-78, doi:10.1175/JTECH-D-14-00054.1.

Del Genio, A. D., 2011: Representing the sensitivity of convective cloud systems to tropospheric humidity in general circulation models Surv. Geophys., 33, 637-656, doi:10.1007/s10712-011-9148-9.

Desbois, M., R. Roca, L. Eymard, N. Viltard, M. Viollier, J. Srinivasan, and S. Narayanan, 2003: The Megha-Tropiques mission. Atmospheric and Oceanic Processes, Dynamics, and Climate Change,
Z. Sun, F.-F, Jin, and T. Iwasaki, Eds., International Society for Optical Engineering (SPIE Proceedings, Vol. 4899), 172, doi:10.1117/12.466703.

—, M. Capderou, L. Eymard, R. Roca, N. Viltard, M. Viollier, and N. Karouche, 2007: Megha Tropiques, un satellite hydrométéorologique franco-indien (Megha Tropiques, a FrenchIndian hydrometeorological satellite). Meteorologie, 57, 19-27, doi:10.4267/2042/18185.

Dessler, A. E., and S. C. Sherwood, 2009: A matter of humidity. Science, 323, 1020-1021, doi:10.1126/science.1171264.

Dirksen, R. J., M. Sommer, F. J. Immler, D. F. Hurst, R. Kivi, and H. Vömel, 2014: Reference quality upper-air measurements: GRUAN data processing for the Vaisala RS92 radiosonde. Atmos. Meas. Technol., 7,4463-4490, doi:10.5194/amt-7-4463-2014.

English, S. J., and T. J. Hewison, 1999: A fast generic millimeterwave emissivity model. Microwave Remote Sensing of the Atmosphere and Environment, T. Hayasaka et al., Eds., International Society for Optical Engineering (SPIE Proceedings, Vol. 3503), 288-300, doi:10.1117/12.319490.

Eymard, L., and Coauthors, 2002: The SAPHIR humidity sounder. Notes des activités instrumentales de l'IPSL 24, 17 pp.

Garand, L., and Coauthors, 2001: Radiance and Jacobian intercomparison of radiative transfer models applied to HIRS and AMSU channels. J. Geophys. Res., 106, 24 017-24 031, doi:10.1029/2000JD000184.

GCOS, 2013: The GCOS Reference Upper-Air Network (GRUAN) guide. WMO Integrated Global Observing System Tech. Rep. 2013-03/Global Climate Observing System Rep. GCOS-171, 116 pp. [Available online at http://www.wmo.int/ pages/prog/gcos/Publications/gcos-171.pdf.]

Gierens, K., K. Eleftheratos, and L. Shi, 2014: 30 years of HIRS data of upper tropospheric humidity. Atmos. Chem. Phys., 14, 7533-7541, doi:10.5194/acp-14-7533-2014.

Gohil, B. S., R. M. Gairola, A. K. Mathur, A. K. Varma, C. Mahesh, R. K. Gangwar, and P. K. Pal, 2013: Algorithms for retrieving geophysical parameters from the MADRAS and SAPHIR sensors of the Megha-Tropiques satellite: Indian scenario. Quart. J. Roy. Meteor. Soc., 139, 954-963, doi:10.1002/qj.2041.

Goldberg, M. D., D. S. Crosby, and L. Zhou, 2001: The limb adjustment of AMSU-A observations: Methodology and validation. J. Appl. Meteor., 40, 70-83, doi:10.1175/ 1520-0450(2001)040<0070:TLAOAA $>2.0$. CO;2.

Greenwald, T. J., and S. A. Christopher, 2002: Effect of cold clouds on satellite measurements near $183 \mathrm{GHz}$. J. Geophys. Res., 107, 4170, doi:10.1029/2000JD000258.

Held, I. M., and B. J. Soden, 2000: Water vapor feedback and global warming. Annu. Rev. Energy Environ., 25, 441-475, doi:10.1146/ annurev.energy.25.1.441.

- and K. M. Shell, 2012: Using relative humidity as a state variable in climate analysis. J. Climate, 25, 2578-2582, doi:10.1175/ JCLI-D-11-00721.1.

Hong, G., G. Heygster, J. Miao, and K. Kunzi, 2005: Detection of tropical deep convective clouds from AMSU-B water vapor channels measurements. J. Geophys. Res., 110, D05205, doi:10.1029/2004JD004949.

, - - J. Notholt, and S. A. Buehler, 2008: Interannual to diurnal variations in tropical and subtropical deep convective clouds and convective overshooting from seven years of AMSU-B measurements. J. Climate, 21, 41684189, doi:10.1175/2008JCLI1911.1.

Hurley, J. V., and J. Galewsky, 2010: A last saturation diagnosis of subtropical water vapor response to global warming. Geophys. Res. Lett., 37, L06702, doi:10.1029/2009GL042316. 
Immler, F. J., J. Dykema, T. Gardiner, D. N. Whiteman, P. W. Thorne, and $\mathrm{H}$. Vömel, 2010: Reference quality upper-air measurements: Guidance for developing GRUAN data products. Atmos. Meas. Technol., 3, 1217-1231, doi:10.5194/amt-3-1217-2010.

Jackson, D. L., and J. J. Bates, 2001: Upper tropospheric humidity algorithm assessment. J. Geophys. Res., 106D, 32 259-32 270, doi:10.1029/2001JD000348.

Karouche, N., C. Goldstein, A. Rosak, C. Malassingne, and G. Raju, 2012: Megha-Tropiques satellite mission: In flight performances results. Proc. Int. Geoscience and Remote Sensing Symp., Munich Germany, IEEE, 4684-4687.

Kelly, B. C., 2007: Some aspects of measurement errors in linear regression of astronomical data. Astrophys. J., 665, 1489-1506, doi:10.1086/519947.

Matricardi, M., F. Chevallier, G. Kelly, and J.-N. Thépaut, 2004: An improved general fast radiative transfer model for the assimilation of radiance observations. Quart. J. Roy. Meteor. Soc., 130, 153-173, doi:10.1256/qj.02.181.

Miloshevich, L. M., A. Paukkunen, H. Vömel, and S. J. Oltmans, 2004: Development and validation of a time lag correction for Vaisala radiosonde humidity measurements. J. Atmos. Oceanic Technol., 21, 1305-1327, doi:10.1175/1520-0426(2004)021<1305: DAVOAT $>2.0 . \mathrm{CO} ; 2$.

— - H. Vömel, D. N. Whiteman, and T. Leblanc, 2009: Accuracy assessment and correction of Vaisala RS92 radiosonde water vapor measurements. J. Geophys. Res., 114, D11305, doi:10.1029/ 2008JD011565.

Nash, J., T. Oakley, H. Vömel, and L. Wei, 2011: WMO intercomparison of high quality radiosonde systems. World Meteorological Organization Instruments and Observing Methods Rep. 107, WMO/TD-No. 1580, 238 pp. [Available online at http://www.wmo.int/pages/prog/www/IMOP/publications/IOM107_Yangjiang.pdf.]

Pierrehumbert, R. T., 1995: Thermostats, radiator fins, and the local runaway greenhouse. J. Atmos. Sci., 52, 1784-1806, doi:10.1175/1520-0469(1995)052<1784:TRFATL > 2.0.CO;2.

_ tropical humidity by large-scale advection. Geophys. Res. Lett., 25, 4537-4540, doi:10.1029/1998GL900203.

Prigent, C., F. Aires, and W. B. Rossow, 2006: Land surface microwave emissivities over the globe for a decade. Bull. Amer. Meteor. Soc., 87, 1573-1584, doi:10.1175/BAMS-87-11-1573.

Roca, R., P. Chambon, I. Jobard, P.-E. Kirstetter, M. Gosset, and J.-C. Bergès, 2010: Comparing satellite and surface rainfall products over West Africa at meteorologically relevant scales during the AMMA campaign using error estimates. J. Appl. Meteor. Climatol., 49, 715-731, doi:10.1175/2009JAMC2318.1.

_, R. Guzman, J. Lemond, J. Meijers, L. Picon, and H. Brogniez, 2011: Tropical and extra-tropical influences on the distribution of free tropospheric humidity over the intertropical belt. Surv. Geophys., 33, 565-583, doi:10.1007/s10712-011-9169-4.

Ryoo, J.-M., D. W. Waugh, and A. Gettelman, 2008: Variability of subtropical upper tropospheric humidity. Atmos. Chem. Phys., 8, 2643-2655, doi:10.5194/acp-8-2643-2008.

Saunders, R. W., T. J. Hewison, S. J. Stringer, and N. C. Atkinson, 1995: The radiometric characterization of AMSU-B. IEEE Trans. Microwave Theory, 43, 760-771, doi:10.1109/22.375222.

_ M. Matricardi, and P. Brunel, 1999: An improved fast radiative transfer model for assimilation of satellite radiance observation. Quart. J. Roy. Meteor. Soc., 125, 1407-1425, doi:10.1002/qj.1999.49712555615.
Schaerer, G., and T. T. Wilheit, 1979: A passive microwave technique for profiling of atmospheric water vapor. Radio Sci., 14, 371-375, doi:10.1029/RS014i003p00371.

Schmetz, J., and O. M. Turpeinen, 1988: Estimation of the upper tropospheric relative humidity field Meteosat water vapor image data. J. Appl. Meteor., 27, 889-899, doi:10.1175/ 1520-0450(1988)027<0889:EOTUTR>2.0.CO;2.

Schröder, M., R. Roca, L. Picon, A. Kniffka, and H. Brogniez, 2014: Climatology of free tropospheric humidity: Extension to the SEVIRI era, evaluation and exemplary analysis. Atmos. Chem. Phys., 14, 11 129-11 148, doi:10.5194/acp-14-11129-2014.

Seidel, D. J., and Coauthors, 2009: Reference upper-air observations for climate: Rationale, progress, and plans. Bull. Amer. Meteor. Soc., 90, 361-369, doi:10.1175/2008BAMS2540.1.

Sherwood, S. C., E. R. Kursinski, and W. G. Read, 2006: A distribution law for free-tropospheric relative humidity. J. Climate, 19, 6267-6277, doi:10.1175/JCLI3978.1.

—, W. Ingram, Y. Tsushima, M. Satoh, M. Roberts, P. L. Vidale, and P. A. O'Gorman, 2010a: Relative humidity changes in a warmer climate. J. Geophys. Res., 115, D09104, doi:10.1029/ 2009JD012585.

—, R. Roca, T. M. Weckwerth, and N. G. Andronova, 2010b: Tropospheric water vapor, convection and climate. Rev. Geophys., 48, RG2001, doi:10.1029/2009RG000301.

Sivira, R. G., H. Brogniez, C. Mallet, and Y. Oussar, 2015: A layeraveraged relative humidity profile retrieval for microwave observations: Design and results for the Megha-Tropiques payload. Atmos. Meas. Techniques, 8, 1055-1071, doi:10.5194/ amt-8-1055-2015.

Soden, B. J., and F. P. Bretherton, 1993: Upper tropospheric relative humidity from the GOES $6.7 \mu \mathrm{m}$ channel: Method and climatology for July 1987. J. Geophys. Res., 98, 16 669-16 688, doi:10.1029/93JD01283.

—, D. L. Jackson, V. Ramaswamy, M. D. Schwarzkopf, and X. Huang, 2005: The radiative signature of upper tropospheric moistening. Science, 310, 841-844, doi:10.1126/ science. 1115602 .

Spencer, R. W., and W. D. Braswell, 1997: How dry is the tropical free troposphere? Implications for a global warming theory. Bull. Amer. Meteor. Soc., 78, 1097-1106, doi:10.1175/ 1520-0477(1997)078<1097:HDITTF>2.0.CO;2.

Stephens, G. L., D. L. Jackson, and I. Wittmeyer, 1996: Global observations of upper-tropospheric water vapor derived from TOVS radiance data. J. Climate, 9, 305-326, doi:10.1175/ 1520-0442(1996)009<0305:GOOUTW >2.0.CO;2.

Vömel, H., and Coauthors, 2007: Radiation dry bias of the Vaisala RS92 humidity sensor. J. Atmos. Oceanic Technol., 24, 953 963, doi:10.1175/JTECH2019.1.

Wang, J., L. Zhang, A. Dai, F. Immler, M. Sommer, and H. Vömel, 2013: Radiation dry bias correction of Vaisala RS92 humidity data and its impact on historical radiosonde data. J. Atmos. Oceanic Technol., 30, 197-214, doi:10.1175/JTECH-D-12-00113.1.

Wang, J. R., and L. A. Chang, 1990: Retrieval of water vapor profiles from microwave radiometric measurements near 90 and $183 \mathrm{GHz}$. J. Appl. Meteor., 29, 1005-1013, doi:10.1175/ 1520-0450(1990)029<1005:ROWVPF $>2.0 . \mathrm{CO} ; 2$.

Wilheit, T. T., 1990: An algorithm for retrieving water vapor profiles in clear and cloudy atmospheres from $183 \mathrm{GHz}$ radiometric measurements: Simulation studies. J. Appl. Meteor., 29, 508-515, doi:10.1175/1520-0450(1990)029<0508: AAFRWV $>2.0 . \mathrm{CO} ; 2$. 